\title{
Heating properties of carbon fibers by using direct resistance heating
}

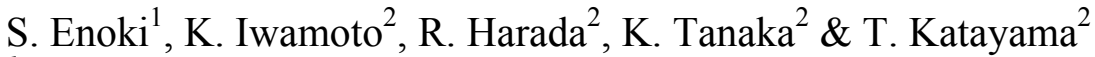 \\ ${ }^{1}$ Departmet of Mechanical Engineering, \\ Nara National College of Technology, Japan \\ ${ }^{2}$ Department of Biomedical Engineering, Doshisha University, Japan
}

\begin{abstract}
In the automobile industry, reduction of car weight is needed to deal with environmental issues. Recently, Carbon Fiber Reinforced Plastics (CFRP) is expected to be used for lightweight component parts. The application of CFRP will become possible to reduce car weights, because CFRP has higher specific strength and specific rigidity. However the cost of CFRP is so high that the use of CFRP does not increase. In addition, it is expected to use thermoplastics as a matrix of CFRP in consideration of recyclability.

To mold Carbon Fiber Reinforced Thermoplastics (CFRTP), it is necessary to impregnate carbon fiber with thermoplastic resin by heating the materials. There are electromagnetic induction heating and direct resistance heating for heating method. The electromagnetic induction heating has a high production cost because of complicated equipment. On the other hand the direct resistance heating is performed with a simple piece of equipment and low consumed power. It is better to use direct resistance heating for low-cost CFRTP molding.

We propose a method of CFRTP molding process using direct resistance heating of carbon fibers in non crimp fabric (NCF). In this paper, the resistance heating characteristic of NCF and the influence of resistance heating upon mechanical properties of carbon fiber were discussed. The temperature distribution of $0^{\circ}$ and $90^{\circ}$ layer were sufficient and it took 70 s to reach to $250^{\circ} \mathrm{C}$ on temperature history when heat is applied to the NCF $\left[0^{\circ} / 90^{\circ}\right]$ using direct resistance heating. From the results of tensile tests of single carbon fiber, tensile strength was not decreased by resistance heating at $300^{\circ} \mathrm{C}$ for 300 s.

Keywords: carbon fiber, non crimp fabric (NCF), direct resistance heating.
\end{abstract}




\section{Introduction}

In the automobile industry, it is necessary to reduce weight of cars for better fuel consumption economy. Recently Carbon Fiber Reinforced Plastics (CFRP) is expected to be used for lightweight component parts [1]. The application of CFRP will become possible to reduce car weights, because CFRP has higher specific strength and specific rigidity than conventional lightweight materials such as high strength steel and aluminum alloy [2]. However CFRP has the issue of high cost and low recycling of thermosetting resins, therefore CFRP is used only in non-mass-produced cars.

Carbon Fiber Reinforced Thermoplastics (CFRTP) that are used thermoplastic resin for the matrix is expected. This is due to CFRTP being better in recyclability and productivity than CFRP. Therefore CFRTP is suitable for the mass-produced cars parts [3]. In order to make effective use of mechanical properties of carbon fiber, it is necessary to use continuous fiber as a reinforcing material. For semi products with continuous fibers, there are non crimp fabric (NCF) and fabric as continuous fiber, therefore NCF is superior to fabric in strength. NCF with non-woven cloth was developed for semi products of CFRTP, because it is superior in terms of production cost and handling of materials.

In the molding of CFRTP with the semi product which consists of carbon fiber NCF and non-woven cloth, it is necessary to impregnate carbon fiber NCF with thermoplastic resin by heating the semi product. There are electromagnetic induction heating and direct resistance heating for heating method. When an electrical current runs through a coil around a mold, a magnetic field will be generated. The magnetic field penetrates the mold placed inside the coil, and creates induced currents on the mold surface. Since the current concentrates within the mold surface, the mould surface generates heat by the joule heating [4]. However facilities for efficiently inducing current become complicated and the equipment cost is high. Direct resistance heating is a heating method that may solve these issues. When an electrical current runs through the materials, it will be heated by joule heat. Therefore this method can run with simple equipment and low consumed power. This heating method already has been applied for metal heating and CFRTP welding [5-7]. By using direct resistance electrical heating through the materials, efficient molding process of CFRTP can be achieved.

In this study, heating properties of carbon fiber NCF were evaluated for the development of CFRTP molding technique using direct resistance heating. To clarify the heating properties of carbon fibers by direct resistance heating, temperature uniformity and history was evaluated. Single carbon fibers were obtained from NCF heated by direct resistance heating. The mechanical characteristic of the single carbon fibers were assessed by tensile test. 


\section{Direct resistance heating characteristic of carbon fibers}

\subsection{Materials and experimental methods}

The non-crimp stitched carbon fabric of $\left[0^{\circ} / 90^{\circ}\right]$ in the weight per unit area of $300 \mathrm{~g} / \mathrm{m}^{2}$, using PAN-based carbon fibers, were used. Specimens with dimensions of $100 \mathrm{~mm}$ in length and $25 \mathrm{~mm}$ in width, were cut from this carbon fiber NCF.

In order to compare the temperature distributions and histories of both sides of the NCF $0^{\circ}$ and $90^{\circ}$ orientation during direct resistance heating of the NCF, temperature distributions and histories of each surface were observed. Fig. 1 shows schematic drawing of temperature distribution measurement. Both $10 \mathrm{~mm}$ of the ends of the carbon fiber NCF were fixed with clips and connected to the high-frequency power supply (T162-6014AAH, THAMWAY, JAPAN) by using cables. The power was supplied to the carbon fiber NCF through the impedance converter (T010-6012A, THAMWAY, JAPAN). In conditions, frequency was $20 \mathrm{kHz}$ and impedance ratio was power: load $=9: 1$. When the temperature distribution of the layer at $0^{\circ}$ orientation has reached $250^{\circ} \mathrm{C}$, the temperature distribution of both layers were observed by using infrared thermography (TVS500, NEC Avio, JAPAN). When the specimens were cut from carbon fiber NCF, fibers with both end parts against fibers of $0^{\circ}$ orientation might cut. In order to investigate the effect of fracture of fibers at $0^{\circ}$ orientation on the temperature distribution, temperature distribution of specimen with $5 \mathrm{~mm}$ width with fibers at $0^{\circ}$ orientation to the central area being cut out was measured as shown in fig. 2 .

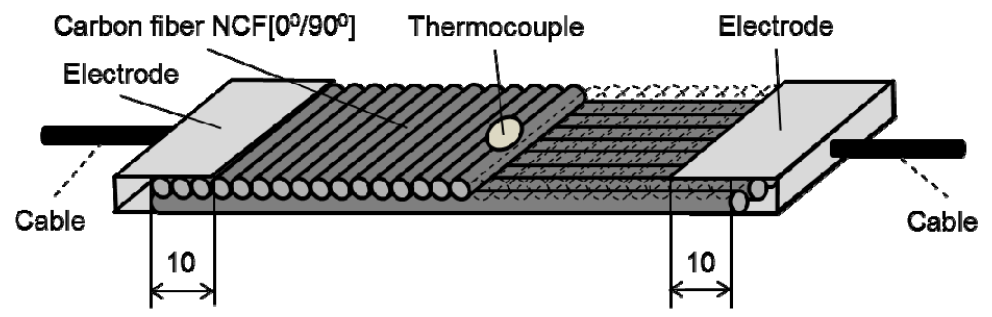

Figure 1: $\quad$ Schematic drawing of temperature distribution measurement.

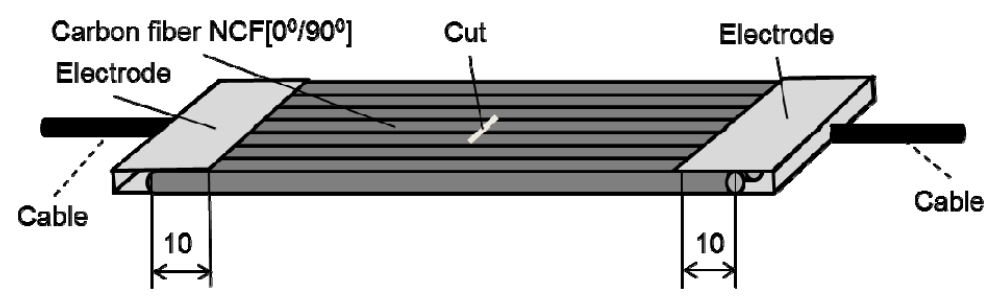

Figure 2: Schematic drawing of temperature distribution measurement with central area cut. 
Current might not flow to $90^{\circ}$ layer in comparison to $0^{\circ}$ layer. In order to investigate the effect of $90^{\circ}$ orientation in electrodes on the temperature distribution, temperature distribution that fibers of $90^{\circ}$ orientation were not connect to the electrodes was measured as shown fig. 3 .

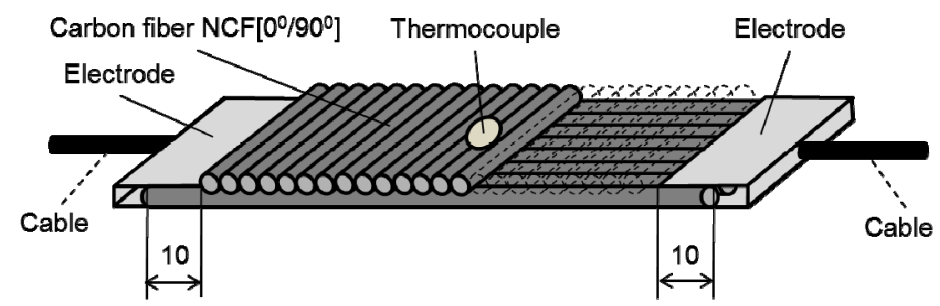

Figure 3: Schematic drawing of temperature distribution measurement without $90^{\circ}$ fibers in the electrodes.

Heating rates were measured between each of the NCF heating by direct resistance heating. Fig. 4 shows Schematic method and thermometric points (13 ) on experiment of NCF heating. The NCF laminated to $\left[0^{\circ} / 90^{\circ}\right]_{2 \mathrm{~S}}$ was used. Direct resistance heating was performed in the same way as the temperature distribution measurement. K-type thermocouples were fitted in between the laminated NCF. The heating rates were measured with thermocouples and recorded per second with graphic recorder (OMRON Co. Ltd., Japan). The direct resistance heating was stopped, after the temperature of the carbon fiber NCF has reached to $250^{\circ} \mathrm{C}$. In addition, the $\mathrm{NCF}$ was naturally cooled to room

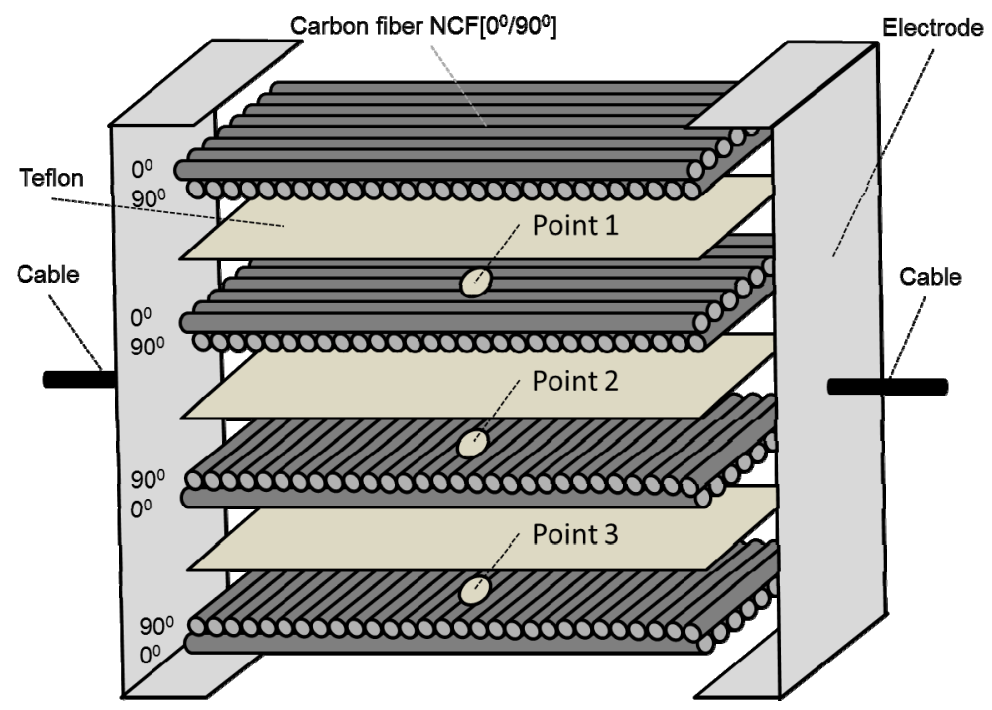

Figure 4: Schematic method and thermometric points (1-3) on experiment of NCF heating. 
temperature. When CFRTP is molded, non-woven fabrics that are insulated are sandwiched in between the NCF. In order to simulate CFRTP molding, Teflon sheets that have heat resistance and insulation properties were sandwiched between the NCF in this experiment. From the results including the heating rates of each layer, we considered the adaptation of CFRTP molding using direct electrical resistance heating.

\subsection{Results and discussion}

Fig. 5 shows the temperature distribution of $0^{\circ}$ layer, when central area of $0^{\circ}$ layer reached $250^{\circ} \mathrm{C}$. From fig. 5(a), the temperature distribution of central area of $0^{\circ}$ layer was uniformly heated to $250^{\circ} \mathrm{C}$. It was confirmed that direct resistance heating could heat carbon fibers NCF. However from fig. 5(a), the temperature of both end areas against fibers of $0^{\circ}$ orientation that were $\mathrm{A}$ areas in fig. 5(a) were lower than the central area, because there were areas of the fibers of $0^{\circ}$ orientation being cut when carbon fiber NCF was cut to the dimension of the specimen. It is caused by the current that was not flowing in the A areas of $0^{\circ}$ layer, therefore the temperature of end areas of $0^{\circ}$ layer could not reach to $250^{\circ} \mathrm{C}$. It is confirmed from Fig. 5 (b) that shows temperature distribution of $0^{\circ}$ layer with $5 \mathrm{~mm}$ width of fibers at $0^{\circ}$ orientation to the central area being cut out was similar to fig. 5(a).

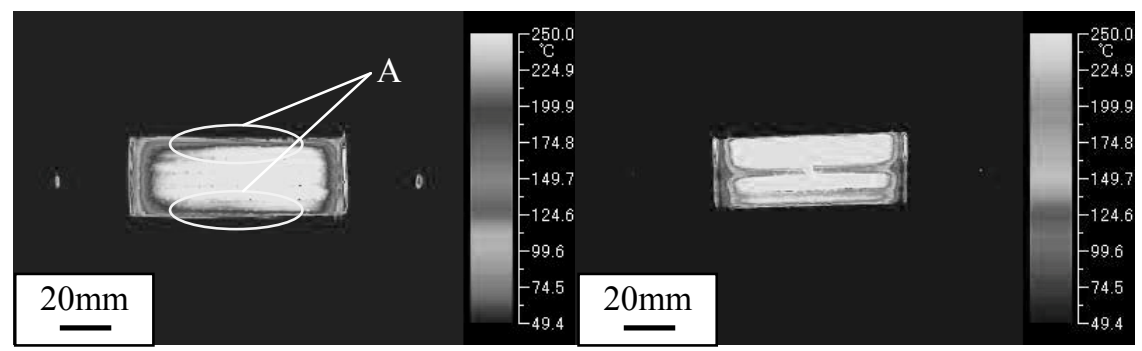

(a) Without cutting.

(b) With cutting.

Figure 5: $\quad$ Temperature distribution of $0^{\circ}$ orientation.

Fig. 6 shows the temperature distribution of $0^{\circ}$ layer when central area of $0^{\circ}$ layer reached to $250^{\circ} \mathrm{C}$. Temperature of $90^{\circ}$ layer was lower than temperature of $0^{\circ}$ layer as shown in fig. 6(a). Current flowed to the fibers of $0^{\circ}$ orientation between the electrodes, and the temperature rise due to heat generated with joule heating of carbon fibers. Current could not flow to the fibers of $90^{\circ}$ orientation between the electrodes, therefore the temperature of $90^{\circ}$ layer was lower than that of $0^{\circ}$ layer. However the temperature of $90^{\circ}$ reached to $250^{\circ} \mathrm{C}$. It was reported that electric conductivities of $0^{\circ}$ layer and $90^{\circ}$ layer are $5.50 \times 10^{3}$ $\left[\Omega^{-1} \mathrm{~m}^{-1}\right]$ and $2.04 \times 10^{2}\left[\Omega^{-1} \mathrm{~m}^{-1}\right]$ in CFRP that its content rate is 0.621 [8]. Therefore current flow of $90^{\circ}$ layer is less than that of $0^{\circ}$ layer. In addition, the temperature distribution of $90^{\circ}$ layer that fibers of $90^{\circ}$ orientation were not connect to the electrodes shown fig. 6(b) was similar to that of fig. 6(a). Fig. 7 


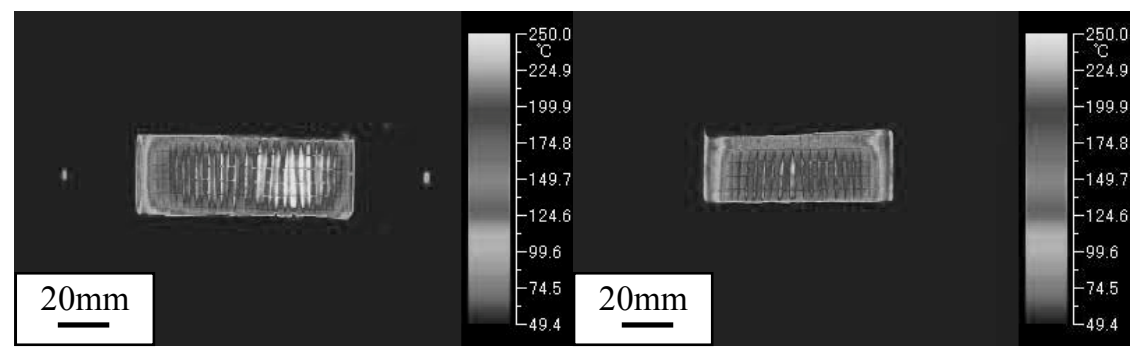

(a) $90^{\circ}$ fibers were connected to the electrodes.

(b) $90^{\circ}$ fibers were not connected to the electrodes.

Figure 6: $\quad$ Temperature distribution of $90^{\circ}$ orientation.

shows temperature histories of both layer of $\mathrm{NCF}\left[0^{\circ} / 90^{\circ}\right]$ when the fibers of $90^{\circ}$ orientation was connected to the electrodes and those with fibers not connected to the electrodes. $90^{\circ}$ layer was heated at lower temperature than temperature of $0^{\circ}$ layer. Temperature of $90^{\circ}$ layer was increased gradually, when $0^{\circ}$ layer is held at $250^{\circ} \mathrm{C}$. Therefore $90^{\circ}$ layer was heated by heat transfer of temperature of $0^{\circ}$ layer, and temperature of $90^{\circ}$ layer does not reach the temperature of $0^{\circ}$ layer.

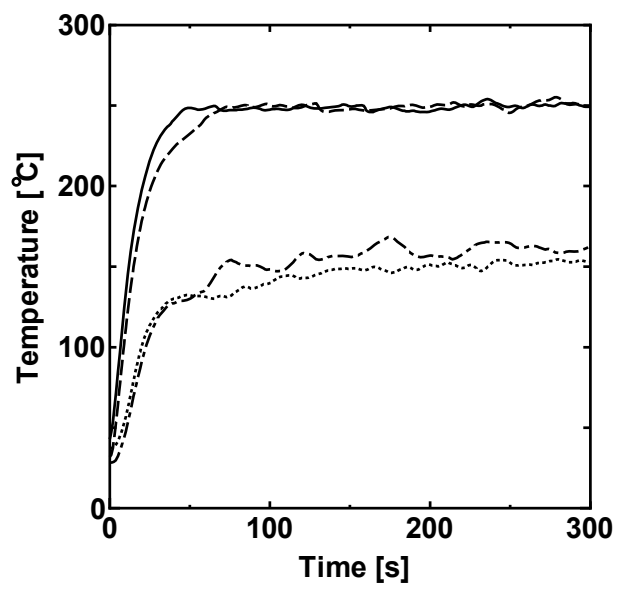

$-0^{\circ}$ layer
$\cdots . . .90^{\circ}$ layer
$--0^{\circ}$ layer that $90^{\circ}$ fibers was not connected
to the electrodes
$--0^{\circ}$ layer that $90^{\circ}$ fibers was not connected
to the electrodes

Figure 7: $\quad$ Temperature history of $\mathrm{NCF}\left[0^{\circ} / 90^{\circ}\right]$. 
Fig. 8 shows the temperature history of NCF $\left[0^{\circ} / 90^{\circ}\right]_{2 S}$ heated using direct resistance heating. From fig. 8, there was no difference in the heating rates of each layer. In addition, it took $70 \mathrm{~s}$ to reach to $250^{\circ} \mathrm{C}$ on the temperature rises of each layer. From the results, the heating rate of the direct resistance heating is equivalent to that of the electromagnetic induction heating system [4]. In addition, there were not differences between temperature histories of each layer due to fiber orientation as shown in fig. 8. Therefore it can heat each layer at same temperature and heating rate due to $90^{\circ}$ layer that was sandwiched $0^{\circ}$ layer in CFRTP molding using direct resistance heating to carbon fiber NCF. In addiction it is possible to prevent the lack of impregnation of the matrix due to the difference of fiber orientation.

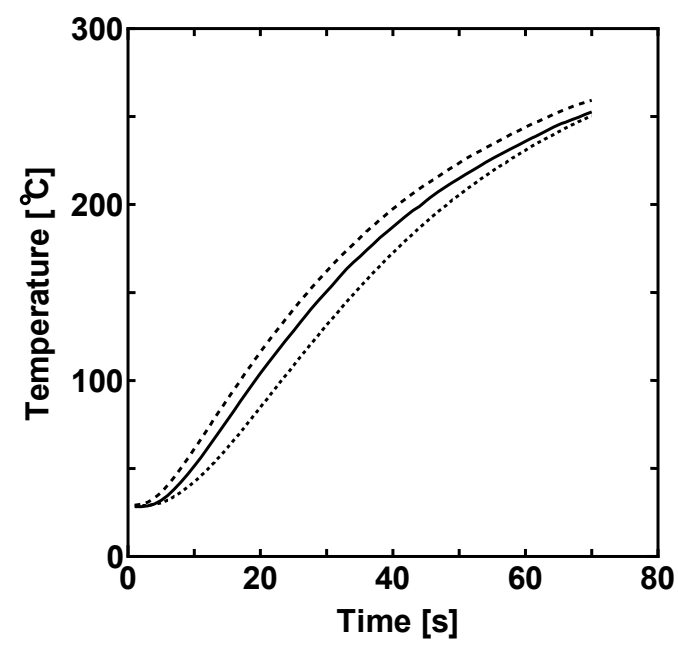

- Point 1 (between $90^{\circ}$ layer and $0^{\circ}$ layer)

Point 2 (between $90^{\circ}$ layer and $90^{\circ}$ layer)

Point 3 (between $0^{\circ}$ layer and $90^{\circ}$ layer)

Figure 8: Temperature history of $\mathrm{NCF}\left[0^{\circ} / 90^{\circ}\right]_{2 \mathrm{~S}}$.

\section{Mechanical characteristic of carbon fibers heated by direct resistance heating}

\subsection{Materials and experimental method}

In order to clarify the influence of direct resistance heating on the mechanical properties of carbon fibers, we evaluated the mechanical characteristic of carbon fibers were heated using direct resistance heating and those which were unheated.

The NCF was heated to $300^{\circ} \mathrm{C}$ for 300 s using direct resistance heating, and the NCF was not heated were used. The direct resistance heating was performed 
in the same way as shown in 2.1. The carbon single fibers were obtained from the central area of the $0^{\circ}$ layer of each carbon fiber NCF for tensile test and measurement for the diameter of carbon single fiber. The fiber length for tensile test and measuring of the fiber diameter were $60 \mathrm{~mm}$ and $10 \mathrm{~mm}$ respectively. The fibers were fixed with cyanoacrylate adhesive in a tab for specimen of tensile test, and were fixed with carbon tape to a tab and coated with platinum to specimens for diameter measurement. Figs. 9 and 10 show the schematic of specimen for tensile test and diameter measurement respectively.

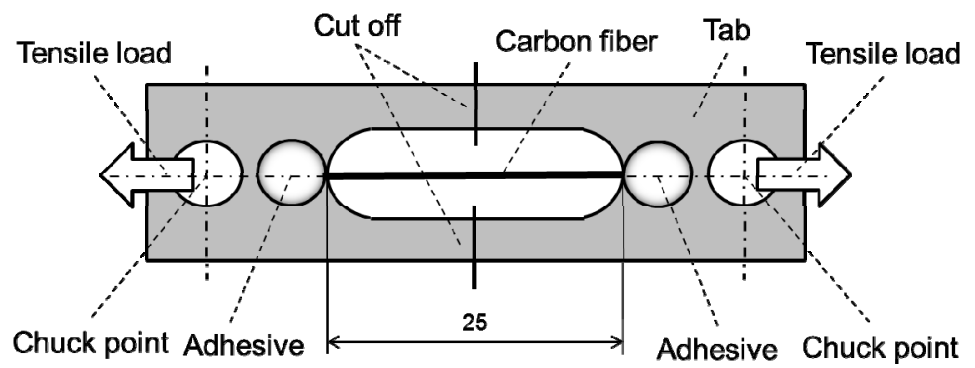

Figure 9: $\quad$ Specimen for tensile test of carbon single fiber.

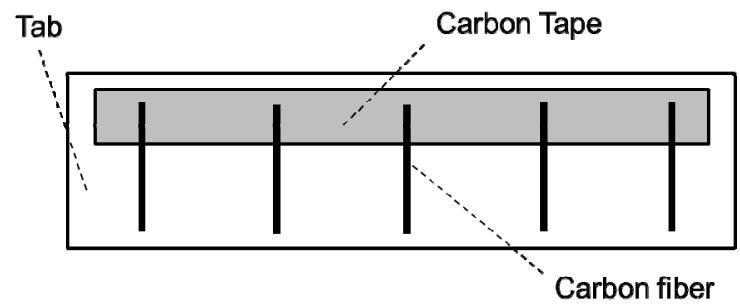

Figure 10: Specimen for diameter measurement of carbon single fiber.

Tensile tests were performed using an electro hydraulic servo controlled testing machine for micro materials (MMT-11NV-2, Shimadzu Co., JAPAN), following the recommended testing procedures as described in JIS-R-7606. Load was applied to the specimens at a displacement rate of $1.67 \times 10^{-5} \mathrm{~m} / \mathrm{s}$. After the ends of the tab were pinned to both end of the tab to chuck point of the testing machine and the middle of tab shown in fig. 9 were cut to load the fiber. The tensile tests were performed to load only the fiber. The diameter measurements of carbon single fibers were observed by SEM (JSM-6390LT, JEOL Ltd., JAPAN) to measure their diameter.

\subsection{Results and discussion}

Tensile strength of carbon single fibers was plotted onto Weibull probability paper as shown in Fig. 11. In addition, table 1 shows the Weibull parameters 
obtained from Fig. 11. The shape parameters $(\mathrm{m})$ of carbon fibers heated and unheated were 7.54 and 7.19 respectively; there were no difference in the dispersion of each data. In addition the scale parameter $\left(\sigma_{0}\right)$ of carbon fiber heated and unheated were $3.49 \mathrm{GPa}$ and $3.36 \mathrm{GPa}$ respectively; there were no difference in scale parameter in the presence and absence of using direct resistance heating. From these results, strength of carbon fibers was not reduced by direct resistance heating at $300^{\circ} \mathrm{C}$ for 300 s.

Table 1: Weibll parameter of CF-1(Room temperature) and CF-2 (temperature: $300^{\circ} \mathrm{C}$, holding time: $300 \mathrm{~s}$ ).

\begin{tabular}{cccc}
\hline Specimen & $\begin{array}{c}\text { Shape parameter } \\
(\mathrm{m})\end{array}$ & $\begin{array}{c}\text { Scale parameter } \\
\left(\sigma_{0}\right)[\mathrm{GPa}]\end{array}$ & $\begin{array}{c}\text { Average strength } \\
{[\mathrm{GPa}]}\end{array}$ \\
CF-1 & 7.19 & 3.36 & 3.18 \\
Room temperature & 7.54 & 3.49 & 3.30 \\
CF-2 & & & \\
$\begin{array}{c}\text { Temperature: } 300^{\circ} \mathrm{C} \\
\text { Holding time: } 300 \mathrm{~s}\end{array}$ & & & \\
\hline
\end{tabular}

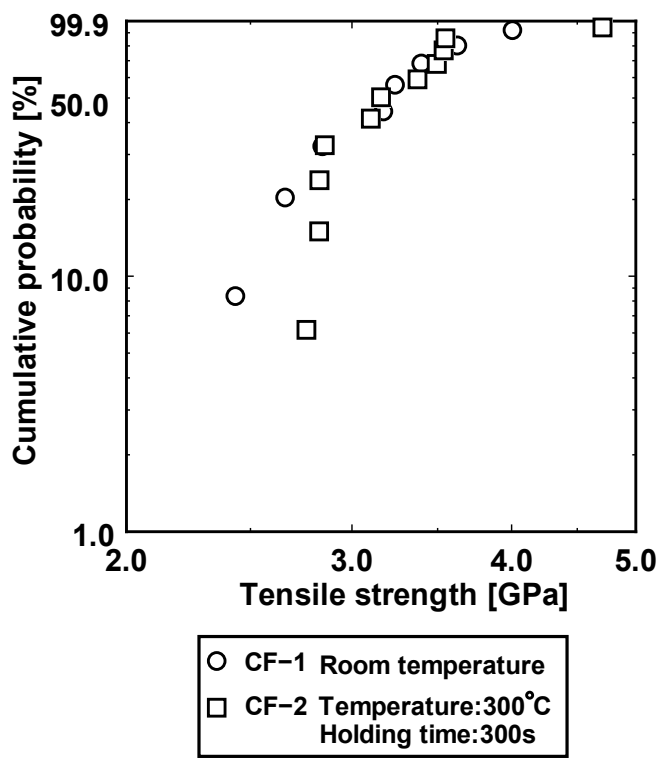

Figure 11: Cumulative probability of carbon fiber strength.

\section{Conclusions}

Heating properties of carbon fiber NCF were evaluated for the development of CFRTP molding technique using direct resistance heating. To clarify the heating 
properties of carbon fibers by direct resistance heating, temperature uniformity and history was recorded. The mechanical characteristic of single carbon fiber that pull are obtained from $\mathrm{NCF}$ heated by direct resistance heating were assessed by tensile test. The investigation yields the following conclusions:

1. It took $70 \mathrm{~s}$ to reach to $250^{\circ} \mathrm{C}$ when carbon fibers $\mathrm{NCF}\left[0^{\circ} / 90^{\circ}\right]_{2 \mathrm{~S}}$ was heated by using direct resistance heating.

2. From the results of tensile tests of single carbon fiber that extracted from the carbon fiber $\mathrm{NCF}$ heated to $300^{\circ} \mathrm{C}$ for 300 s using direct resistance heating, the tensile strength was not reduced.

The direct electrical resistance heating can apply to CFRTP molding.

\section{Acknowledgement}

This study was partially supported by KAKENHI (Japan Society for the Promotion of Science, Grant-in-Aid for Young Scientists (B)) (23760102).

\section{References}

[1] Daisho, Y., Perspectives on Future Motor Vehicle Technologies Associated with Environment and Energy, IATSS Review, Vol.33, No.3, pp. 51-56, 2008.

[2] Shida, R., Tsumuraya, K., Nakatsuka, S. and Takahashi, J., Effect of automobile lightening by CFRP on the world energy saving, The Ninth Japan International SAMPE symposium, pp. 8-13, 2005.

[3] Offringa, A.R., Thermoplastic composites - rapid processing applications, Composites: Part A, Vol.27, pp. 329-336, 1996.

[4] Tanaka, K., Kohashi, N., Kinoshita, Y., Katayama, T. and Uno, K., Compression Molding of Carbon Fiber Reinforced Thermoplastics Using Non-Woven Stitched Multi-Axial Cloth by Means of Induction Heating System, Journal of the Society of Materials Science, Japan, Vol.58, No.7, pp. 642-648, 2009.

[5] Hamada, K., Isaka, K., Doi, D., Yonemitsu, Y. and Iwasaki, S., Application of the Direct Resistance Heating for Stainless Steel/Aluminum Clad Manufacturing Process, The Iron and Steel Institute of Japan (ISIJ), Vol.88, No.2, pp. 16-22, 2002.

[6] Ishiguro, M., Maki, S. and Mori, K., Improvement of product strength and press formability of $\mathrm{Al}-\mathrm{Mg}-\mathrm{Si}$ alloy sheets by resistance heat treatment and artificial aging, Journal of Japan Institute of Light Metals, Vol56, No.6, pp. 313-316, 2006.

[7] Yuan, Q., Hou, M., Mai, Y.M. and Ye, L., Resistance Welding of Carbon Fiber Reinforced Polyetherimide Composite, Journal of Thermoplastics Composite Materials, Vol.14, pp. 2-19, 2001.

[8] Todoroki, A., Tanaka, M. and Shimamura, Y., "Measurement of orthotropic electric conductance of CFRP laminates and analysis of the effect on delamination monitoring with an electric resistance change method", Composites Science and Technology, Vol.62, pp. 619-628, 2002. 